\title{
TRASPLANTE RENAL: DILEMAS Y BIOÉTICA
}

\author{
Luis Alberto Blanco Rubio MD*
}

\section{Resumen}

El progreso de la ciencia y en especial el de los trasplantes de riñón amerita muchas reflexiones éticas, pues no todos los dilemas que se presentan se han solucionado y algunos no han sido tomados como tales. Los donantes vivos pueden ser sujetos a coacción, pues adquieren un compromiso con la familia, la sociedad y el equipo de salud para donar su riñón. Muchos en realidad no lo quieren hacer, aunque en los libros aparezca la donación como el mayor acto de amor y solidaridad. No todos los hijos quieren a sus padres y viceversa, ni todos los hermanos se quieren entre sí. Son muy importantes los conceptos de solidaridad y amor, que no suelen aparecer de manera espontánea en la vida de los individuos. Amor es un arte que implica dar pero de una forma madura. ¿Tendrán todos los donantes esta capacidad de dar? Si no la tienen es probable que estén siendo víctima de una coacción. Como existen tantos dilemas éticos con el trasplante de riñón, la bioética ayuda a dar respuesta a tantas inquietudes para poder colaborar con más efectividad a los involucrados en él.

Palabras clave: trasplante, trasplante intrafamiliar, coacción, autonomía, amor, solidaridad.

Abreviaturas: TR, trasplante renal.

\section{KIDNEY TRANSPLANTATION: BIOETHICS AND DILEMMAS}

\section{Abstracts}

Scientific breakthroughs, especially kidney transplantation, deserve serious ethical reflections for not all dilemmas that arise have been addressed and some have not been contemplated as such. Live donors could be subject to coercion in favor of donating their kidney for they have acquired a commitment with their relatives, society and health teams. Although donation appears in literature as the greatest act of love and solidarity not all live donors are actually willing to give up their kidney. Not all sons and daughters love their parents or parents love their children, nor all siblings love each other. Such important concepts as solidarity and love are not commonly manifest spontaneously in the life of individuals. Love is considered an art which implies giving in a mature manner. Will all donors have this ability? If they lack this ability they are more likely being victims of coercion. As various ethical dilemmas on kidney transplantation exist, bioethics has helped answer many questions in order to furnish an effective support to all who are involved.

Key words: transplantation, living-related donor transplantation, coercion, autonomy, love, solidarity.

Fecha recibido: febrero 13 de 2009 - Fecha aceptado: marzo 5 de 2009

* Médico urólogo, Hospital de San José. Sección de trasplante renal. Especialista en Bioética, Universidad El Bosque. Vicepresidente de la
Sociedad de Cirugía de Bogotá - Hospital de San José. Profesor Titular, Fundación Universitaria de Ciencias de la Salud. Bogotá D.C. Colombia. 


\section{Introducción}

El TR ha sido desde hace varios años un aliciente para los enfermos con insuficiencia renal. El pronóstico y la sobrevida de los implantes ha mejorado en forma dramática a partir del descubrimiento de la ciclosporina en 1978, pero esto no quiere decir que sea la panacea para el tratamiento, sino una ayuda más para mejorar su calidad vida. Aunque el TR sea una importante herramienta para el tratamiento de los pacientes con insuficiencia renal crónica, se plantean serios dilemas éticos, varios de ellos aún no resueltos y otros no reconocidos como tales en especial en los casos de donante vivo. Por ejemplo, se habla que donar un órgano es el mayor acto de generosidad, compasión, altruismo, solidaridad y amor. Pero, ¿En realidad lo es? ¿El donante sabe el significado de estos términos? ¿Si no lo sabe o no tiene estos sentimientos, está siendo víctima de una coacción? Será a través de la bioética que nos podemos aproximar a dar una respuesta a muchas inquietudes y así poder ayudar con más efectividad a todos los involucrados en el trasplante.

\section{Historia}

La era moderna del trasplante de órganos comenzó a principios del siglo XX gracias al descubrimiento de nuevas técnicas de suturas. En particular los aportes de Carrel (1914) permitieron establecer las bases de las anastomosis vasculares.

En 1933 se efectuó el primer TR de humano a humano por el cirujano ucraniano Jul Varonoy. El injerto nunca funcionó y el receptor falleció a los pocos días de la operación. En 1947 Hume realizó un TR en una paciente con insuficiencia renal posparto, mediante anastomosis de los vasos de un riñón de cadáver a los braquiales del receptor. Este injerto funcionó de manera transitoria y la paciente sobrevivió, lo que impulsó el trabajo de los cirujanos de la época en esta área.

El hecho más sobresaliente se produce en 1954 en Boston cuando Murray documentó la sobrevida permanente de un trasplante renal entre hermanos gemelos. Después, comenzaron a formarse numerosos centros de trasplante en todo el mundo. Durante este mismo período se introdujo la azatioprina que permitió el desarrollo del tras- plante con donante cadavérico, pero más importante aún fue la introducción de la ciclosporina en 1980, la cual mejoró en forma significativa la sobrevida de los injertos e impulsó el trasplante de otros órganos como hígado, corazón y pulmón.

En la Sociedad de Cirugía de Bogotá-Hospital de San José practicamos el primer trasplante, que en realidad fue un auto-trasplante, en 1979 a un paciente que presentó ruptura de un aneurisma de una de las ramas de la arteria renal izquierda. En 1982 hicimos el primer trasplante de donante cadavérico con buenos resultados. En 1984 practicamos el primero con donante vivo, por fortuna con éxito.

\section{Reflexiones éticas del TR}

La historia de la bioética es paralela a la del TR. Primero, porque su reciente nacimiento fue por la misma época y segundo, porque los problemas que va afrontando la donación del riñón aparecen al mismo tiempo que otros que plantea la bioética en relación con la investigación en humanos. La bioética surgió ante la necesidad de resolver problemas que se presentaban con el desarrollo acelerado de la ciencia biomédica en los últimos años. Por ejemplo, con el desarrollo de los trasplantes se plantearon serios dilemas éticos, ya que se realizaban en especial con familiares y no entre no relacionados o bien entre receptor y cadáver, debido a que en esta última situación se producían fuertes rechazos con fatales consecuencias, en parte por el desconocimiento del mecanismo y tratamiento inmunológicos. Cuando se descubrió la ciclosporina la situación cambió en forma importante.

\section{Consentimiento informado}

Según Pablo Simón Lorda el consentimiento debe estar por fuera de toda coacción. Según él, debe existir la libertad externa, sin ningún tipo de presión ya sea de la familia, del médico o de la institución a la cual asiste el paciente. Debe existir también una libertad interna en la cual el sujeto moral obra de manera intencional desde su propio ser, es decir, en forma consciente. 
En muchos casos el consentimiento se convierte en un trámite administrativo en que el paciente cree que decide según sus expectativas de vida y valores éticos y sociales respecto a la percepción de su salud, y el médico piensa que con él queda exonerado de toda responsabilidad. Tenemos que darle un giro a esta concepción y tornarla en una relación interpersonal, para poder discutir sin límite de tiempo sobre el tratamiento, con toda sinceridad por parte del paciente y del médico. Hay que entablar una amistad que permita explicar sin interés de por medio, sus mejores opciones de tratamiento y así en el caso de un trasplante intrafamiliar, en un momento dado el donante pueda manifestar con toda confianza, por ejemplo, que se siente coaccionado.

\section{La coacción en el trasplante de donante vivo}

Ya se ha mencionado cómo en los tratados de trasplante se exalta que la donación de un órgano es el mayor acto de generosidad, compasión, altruismo, solidaridad y amor. Me interesa mucho profundizar un poco acerca del significado de estos últimos términos, porque: ¿Estamos seguros de que el donante está actuando con generosidad, solidaridad, amor y quiere donar su órgano? ¿Sabemos qué es en realidad lo que piensa un paciente a quien se le va a practicar un trasplante, o aquel que va a donar su propio riñón en vida?

Cuando se propone al enfermo con insuficiencia renal ya sea por sugerencia de los médicos, del mismo paciente o su familia, que va a ser trasplantado y que el riñón va a ser obtenido de un donante vivo, por lo regular de algún miembro de la familia (madre, padre, hijo, nieto, sobrino, tío) o de un relacionado afectivo (compañero, compañera, esposo, esposa) y no de un cadáver, se supone que el donante está convencido de su intención. Pero se presenta en este momento un dilema: ¿Estamos seguros de que el donante goza de la salud mental suficiente como para dar su riñón con la debida solidaridad, compasión y amor? O para más claridad, ¿Sabe el significado de estos términos y por lo tanto, quiere el individuo en realidad donar su órgano? Es muy importante hacer un diagnóstico preciso, pues de lo contrario estaríamos lesionando la autonomía de esa persona con todas sus consecuencias.
Hemos observado desde 1984, cuando comenzamos a hacer los trasplantes intrafamiliares en el Hospital de San José de Bogotá, que no todas las personas están dispuestas a ser donantes en vida. Por un lado porque sin más razones no quieren donar el riñón y por otro porque no todos los hijos quieren a sus padres, no todos los hermanos se quieren entre sí y lo que parece más duro de aceptar, no todos los padres quieren a sus hijos lo suficiente como para donarles un órgano. Es así como de manera consciente o inconsciente pueden rechazarlo. Esta aseveración está respaldada por una encuesta que se hizo a algunos donantes, en la cual se vio como la mayoría de los que no deseaban serlo no lo manifestaron nunca a sus familiares y en el momento del procedimiento no se atrevieron a negarse. Es desafortunado que cuando se plantea una donación aparece una fuerte presión social, familiar y a veces del grupo de salud, la cual hace que la persona tenga poca opción de decidir con libertad y no tiene más que aceptar. Esta circunstancia puede constituir una violencia o coacción que lesiona su autonomía. A veces el donante sometido a tal presión hace enfermedades psicosomáticas previas a la cirugía como estados gripales o síndromes convulsivos, como lo hemos visto en nuestra institución.

Hemos mencionado que en muchos escritos aparece el amor como motor de la donación. El amor no es un afecto pasivo, sino una actividad que se plasma en el "dar" sin esperar recibir. Quiere decir que amar es dar. Pero, ¿Qué es dar? ¿Quién da? Hay diferentes formas de dar. La egoísta, en la cual se siente que se pierde algo; la mercantilista en la que se da a cambio de recibir; la cristiana en la que dando se alaba a Dios, pero puede ser un sacrificio; la forma madura, que es un grado alto de potencia en donde el dador experimenta potencia, vitalidad y por consiguiente alegría. Es importante determinar en el proceso del trasplante si estamos ante una persona madura que tenga claros estos conceptos. De lo contrario podríamos estar ante un acto, no de amor, sino de coacción en donde vulneramos la autonomía de la persona.

Otro dilema al cual nos enfrentamos cuando descubrimos que el donante no quiere dar su riñón, es cómo explicárselo a los familiares si él no lo ha hecho. Crearíamos un conflicto con los allegados y nuestro deber es 
proteger al paciente ¿Pero cómo? ¿Deberíamos decirles que no hay compatibilidad y esto bastaría? Preguntarían: “¿En qué consiste esa incompatibilidad?” Es necesario respetar la confidencialidad y argumentar la falta de preparación psicológica de la persona para realizar en el momento este tipo de donación.

Existen otros dilemas como el de justicia que está relacionado con la escasez de órganos, la venta o comercio de ellos, la presunción de donación en el caso de trasplantes de cadáveres y otros, pero me pareció de sumo interés tratar el de la coacción en el donante vivo, pues, es difícil de detectar y de solucionar.

\section{Discusión}

Los centros de trasplante deben tener especial cuidado en este aspecto ético para no lesionar la autonomía de las personas y estar atentos a ciertos mecanismos por los cuales se somete a coacción al donante. De todas formas es muy difícil en algunos casos, porque la presión originada por la familia, la sociedad y aún el grupo de salud es de tal magnitud, que el individuo se ve imposibilitado para manifestarse. Como parte de la solución a estos conflictos es necesario promover a través de campañas la donación de órganos en caso de muerte y así fomentar los trasplantes de cadáver, que aunque también tienen dilemas éticos, son menos complejos de solucionar.

\section{Lecturas recomendadas}

- Arévalo Leal S. Donación cadavérica de órganos y tejidos: dilemas bioéticos. En: Seis miradas sobre la bioética clínica. Bogotá : Ediciones El Bosque; 2008. p 49.
- Aristoteles. Ética a Nicómaco. Madrid, España: Real Academia de Ciencias Morales y Políticas; 1918.

- Beauchamp TL, Childress JF. Principios de la bioética biomédica. Barcelona: Masson; 1999.

- Escobar Triana J. Dimensiones ontológicas del cuerpo: una visión filosófica del cuerpo y su relación con el ejercicio de medicina. Bogotá: Universidad el Bosque; 1997.

- Fromm E. La condición Humana Actual. Barcelona: Paidos; 2000.

- Gracia D. Como arqueros al blanco: estudios de bioética. Bogotá: Editorial El Buho; 1994.

- Gracia D. Ética en los confines de la vida. Bogotá: Editorial El Buho; 1998.

- Gracia D. Bioética clínica. Bogotá: Editorial El Buho; 1998.

- Protas J, Childress J. Trasplante de órganos. En: Enciclopedia de bioética. New York: Macmillan; 1978. p. 1852.

- León Salcedo G. Bioética, justicia y salud. Bogotá: Universidad el Bosque; 2006.

- Lorda PS. El consentimiento informado y la participación del enfermo en las relaciones sanitarias. En: Lorda PS. Bioética para clínicos. Madrid, España: Editorial Triacastella; 1999. p. 133-144.

- Platón. La República. Madrid, España: Alianza Editorial; 1999.

- Troncoso Carrasco PA. Trasplante renal. Santiago de Chile: Pontificia Universidad Católica de Chile; 1999.

- Wilkinson S. Bodies for sale: ethics and exploitation in the human body trade. New York: Routledge Taylor and Francis; 2004.

- Zambrano CV. Bioética, justicia sanitaria y diversidad cultural. Bogotá: Universidad del Bosque; 2006. 